\title{
Acute Myocardial Infarction in Pregnancy
}

\author{
E. FLETCHER,* M.D., F.R.C.P. ; E. W. KNOX,* M.D., M.R.C.P.I. \\ P. MORTON,* M.D., M.R.C.P.ED.
}

Brit. med. F., 1967, 3, 586-588

Obstructive coronary artery disease is the rarest form of primary organic heart disease encountered during pregnancy. Myocardial infarction occurring during pregnancy was confirmed for the first time at necropsy by Katz (1921). The first case of recurrent myocardial infarction during pregnancy and labour, with electrocardiographic evidence, was published in 1935 by Reis and Frankenthal. Since then a few further case reports have been published by various authors. Bedford (1964) was able to collect only four cases in the British literature, to which he added one of his own. In a recent review Watson et al. (1960) collected 23 authentic cases of myocardial infarction during pregnancy or labour. To this number may be added the case of Magner (1961), that of Bedford referred to above, and the five cases described in this paper, a total of 30 in the world literature.

This paper presents the clinical and electrocardiographic data of five women who sustained major episodes of acute myocardial infarction while pregnant. During the period 1 January 1955 to 31 December 1966 at least 40,000 patients

- Cardiovascular Unit, Belfast City Hospital, Belfast 9. attended the antenatal clinics of the Belfast City Hospital. The five patients already mentioned were selected from approximately 800 pregnant women referred to the cardiac department for assessment. They were all multigravidae, with an age range of 36-41 years. There was no maternal mortality in connexion with the pregnancies or puerperia. All but one (Case 5) pro-

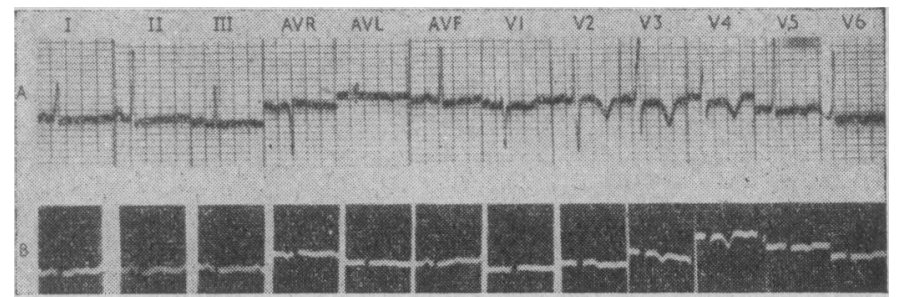

FIG. 1.-Case 1. A (29th week of 4th pregnancy). Sinus rhythm. Abnormal S-T segment and T-wave displacement with grossly abnormal T waves, most pronounced in leads V2-V6. The tracing is consistent with the acute phase of anteroseptal ischaemia or infarction. B (16 days after A). In the interval between the tracings there has been some correction of repolarization, but the underlying myocardium remains abnormal.

Summary of Relevant Data in Five Cases

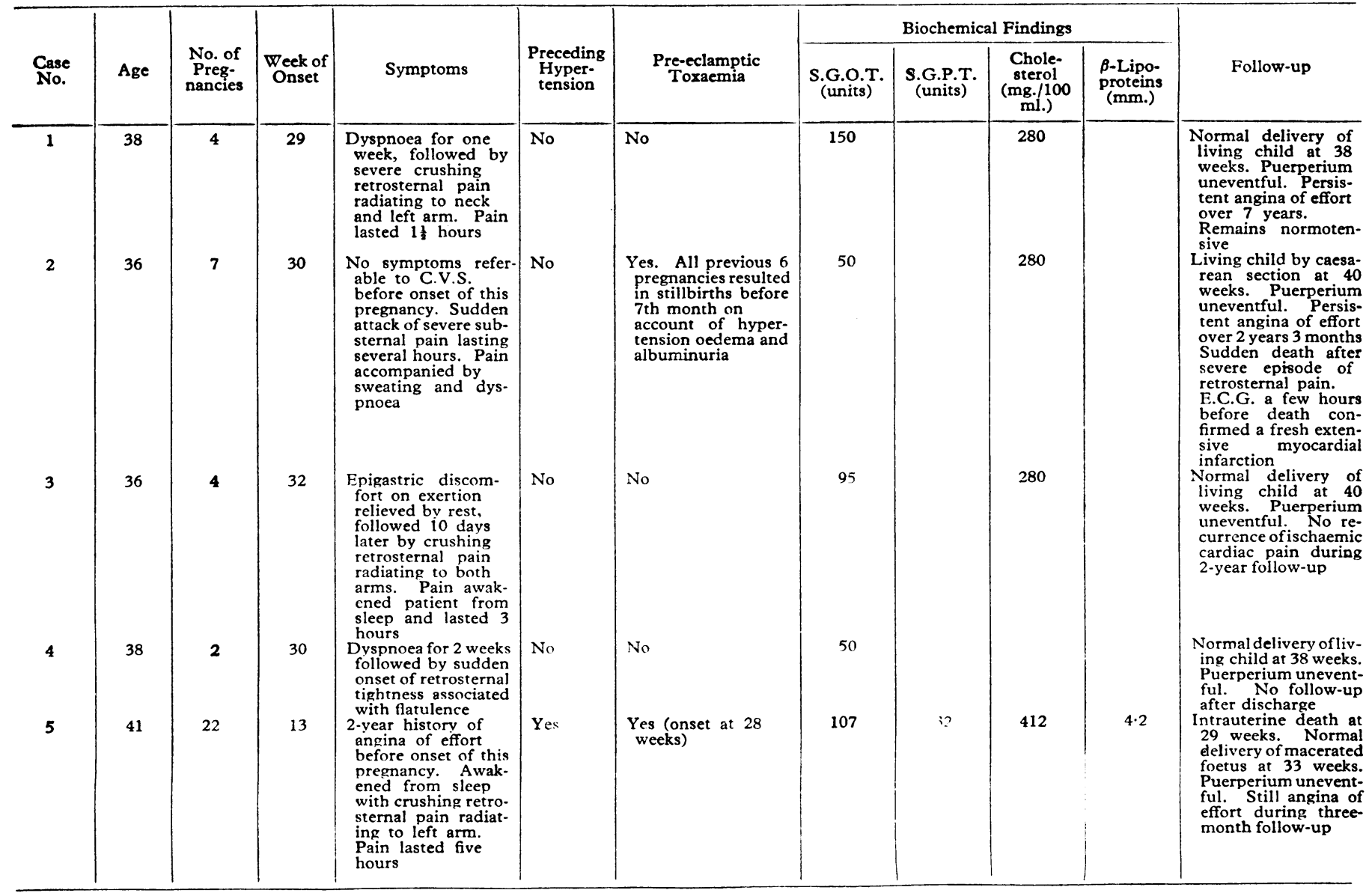


duced healthy children. The cause of the single foetal death was severe pre-eclamptic toxaemia. It was not related to the cardiac status of the mother. Two patients (Cases 2 and 5) had severe pre-eclamptic toxaemia of pregnancy, and this might be a contributing factor for the occurrence of coronary atherosclerosis. The other three women had no general medical condition likely to predispose them to coronary artery disease. The relevant clinical obstetric and biochemical data for each patient are summarized in the Table. Serial electrocardiograms were recorded in each case, and these are shown in Figs. 1-5.

\section{Discussion}

In a review of 45 cases of coronary artery disease associated with pregnancy by Mendelson (1960) 19 had systemic hypertension, 9 had cardiovascular syphilis, and 2 had diabetes mellitus. Two of our patients (Cases 2 and 5) had a systemic disease likely to predispose to coronary atherosclerosis-that is,

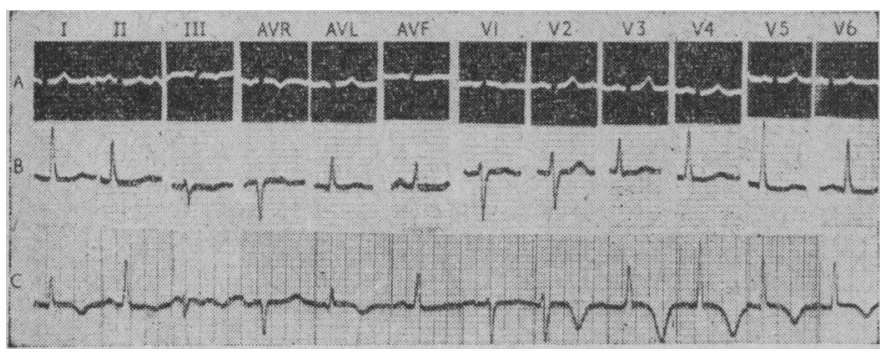

Fig. 2.-Case 2. A (20th week of 7th pregnancy). Normal tracing. B (10 weeks after A). Sinus rhythm. Abnormal S T segment depression in leads 1 , II, and V4 V6. An abnormal tracing when compared with A. C (two weeks after B). Abnormal S-T segment displacement in the limb leads with increased polarity of $T$ waves in leads 1 AVL, and V2-V6. The tracing is consistent with recent anterolateral infarction.

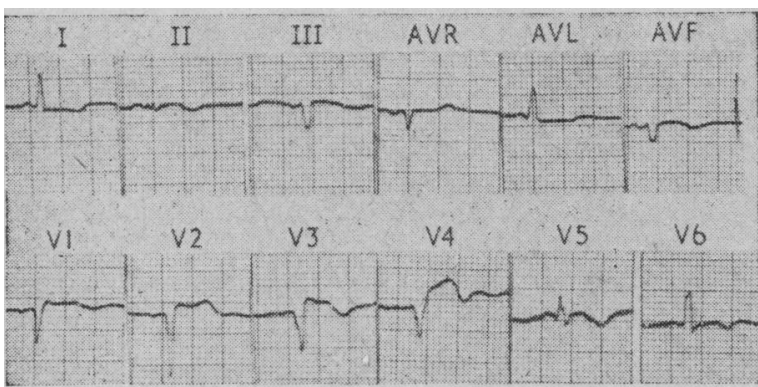

Fig. 3-Case 3 (32nd week of 4th pregnancy). Sinus rhythm. Abnormal Q-S deflections in leads V1-V4. S-T segment and T-wave displacement upwards due to injury current in these leads and also in leads II, III, and AVF. The tracing is consistent with acute myocardial infarction.

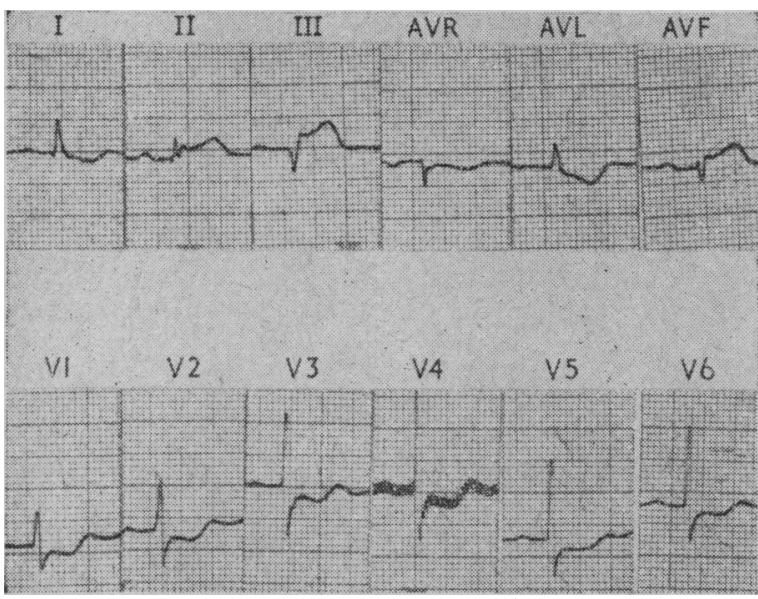

Fig. 4.-Case 4 (30th week of 2nd pregnancy). Sinus rhythm. $P-R$ interval 0.22 second. Abnormal $S$ - T segment and $T$-wave displacement upwards, due to injury current in leads II, III, displacement upwards, due to injury current in leads II, III, and AVF, and downwards in leads 1 , AVL, and V1-V6. The tion and anterior-wall ischaemia. a long history of recurrent toxaemia of pregnancy with hypertension. The underlying disorder in all five cases appears to have been coronary atherosclerosis. In all but one of them the acute infarctions occurred in the third trimester, when the oxygen demand of the tissues is increased and the work load of the heart is at its maximum. During pregnancy the blood chemistry alters significantly; the total cholesterol increases and more is attached to the beta-lipoproteins. The pattern resembles that found in men with ischaemic heart disease (Oliver and Boyd, 1955). These changes are maximal about the thirty-third week, and they take place in spite of the great increase in circulating oestrogens, known effective agents in restoring the non-atherosclerotic plasma lipid pattern (Barr, 1953).

The dynamic factors and biochemical changes referred to above may have predisposed some of our patients to coronary occlusion at the critical weeks of gestation, on the assumption that they already suffered from coronary atherosclerosis. They are not, however, the whole answer, since one patient (Case 5)

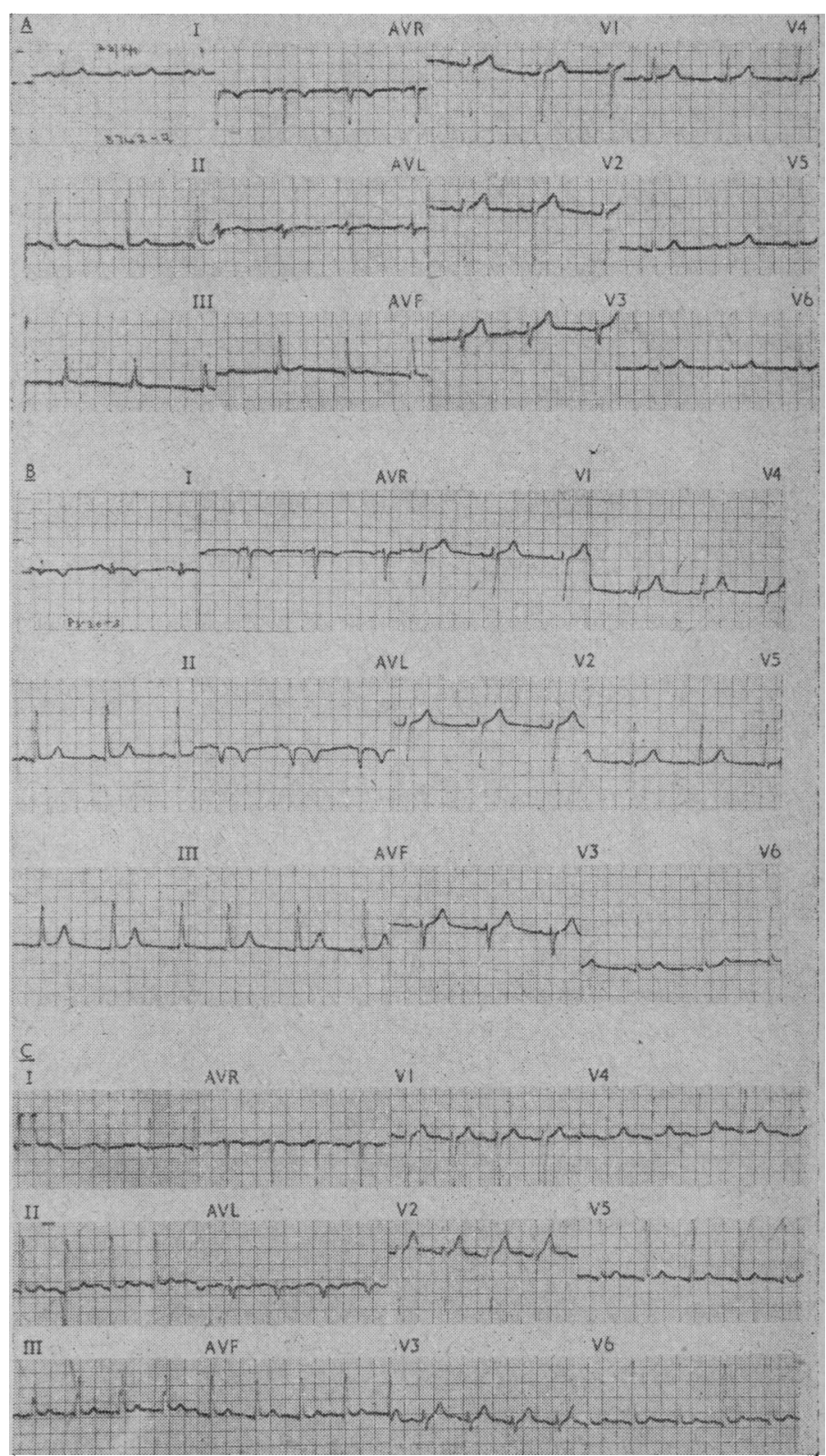

Fig. 5.-Case 5. A (10 months before B). Normal tracing. B (13th week of 22 nd pregnancy-10 months after A). Sinus rhythm. Abnormal $S-T$ segment and $\mathrm{I}$-wave displacement with increased polarity of $\mathrm{T}$ waves in leads I and AVL. Abnormal Q-S deflection in lead AVL. The tracing in leads I and AVL. Abnormal Q-S defiection in lead AVL. The tracing is consistent with recent anterolateral infarction. $\mathrm{C}$ (4 months after B).
In interval following B considerable correction of repolarization has taken place but the tracing still remains abnormal. 
developed her episode of coronary occlusion as early as the thirteenth week of gestation and she was the only one in our series in whom the serum cholesterol was significantly raised.

The diagnosis of myocardial infarction during pregnancy presents clinical and electrocardiographic difficulties. Accessory laboratory investigations for myocardial necrosis have to be interpreted with reservations. Upper abdominal pain, flatulence, and even chest discomfort are so common during normal pregnancy that they may mask ischaemic heart pain. The true nature of such symptoms may be obvious only retrospectively when an incidental electrocardiogram is recorded, as in the case reported by Watson et al. (1960). Normally the erythrocyte sedimentation rate increases progressively, reflecting changes in plasma proteins. Leucocytosis occurs, and at term the white cell count may be as high as $15,000 / \mathrm{cu}$. mm. (Tysoe and Lowenstein, 1950). There is evidence that normally the serum aspartate aminotransferase activity does not deviate, though it may be elevated in toxaemia of pregnancy (Crisp et al., 1959). Serum lactic dehydrogenase is a much less reliable index of myocardial necrosis, as it may be raised in normal pregnancy, and in particular during the puerperium. According to Smith and Gatenby (1958) this enzyme is elevated in $18 \%$ of antepartum patients and in $100 \%$ of postpartum patients.

Objective evidence of myocardial infarction, therefore, will depend on electrocardiographic analysis, and account must be taken of the electrocardiographic changes which may occur during pregnancy when the heart is not primarily involved. In the later months the mean QRS axis may rotate leftwards owing to elevation of the diaphragm (Hollander and Crawford, 1943) and a deep Q deflection may appear in lead III (Thomson et al., 1938). Acute pulmonary embolism may produce abnormal $Q$ deflections, especially in lead III and S-T T segment and $\mathrm{T}$-wave changes, which may mimic postero-diaphragmatic infarction. In addition, electrolyte imbalance may alter the voltage and polarity of the $T$ waves. Intrinsic myorardial disease other than infarction, such as myocarditis of pregnancy, may produce electrocardiographic changes indistinguishable from infarction. In short, electrocardiographic abnormalities must be correlated with all the clinical data. The, subsequent history of our patients supports the view that the grossly abnormal tracings were in fact due to myocardial infarction.

\section{Summary}

Acute myocardial infarction is rare in pregnancy. The cases of five elderly multigravidae suffering from this condition are described. The diagnosis during pregnancy may present clinical and electrocardiographic difficulties. The increased load on the heart and changes in the blood lipids may predispose to acute infarction in late pregnancy in women with pre-existing coronary atherosclerosis.

Our thanks are due to our obstetric colleagues of the Jubilee and Gardner Robb Maternity Hospitals, who kindly referred their patients to us for cardiac assessment.

\section{REFERENCES}

Barr, D. P. (1953). Circulation, 8, 641.

Bedford, J. R. D. (1964). F. Obstet. Gynaec. Brit. Cwlth, 71, 459.

Crisp, W. E., Miesfeld, R. L., and Frajola, W. J. (1959). Obstet. and Gynec., 13, 487.

Hollander, A. G., and Crawford, J. H. (1943). Amer. Heart f., 26, 364.

Katz, H. (1921). Arch. Gynäk., 115, 283.

Magner, D. (1961). ₹. Obstet. Gynaec. Brit. Cwlth, 68, 128.

Mendelson, C. L. (1960). Cardiac Disease in Pregnancy. Philadelphia.

Oliver, M. F. and Boyd, G. S. (1955). Clin. Sci., 14, 15.

Reis, R. A., and Frankenthal, L. E. (1935). Amer. F. Obstet. Gynec., 29, 44.

Smith, W. S., and Gatenby, P. B. B. (1958). Irish f. med. Sci., p. 457.

Thomson, K. J., Cohen, M. E, and Hamilton, B. E. (1938). Amer. F. med. Sci., 196, 819.

Tysoe, F. W., and Lowenstein, L. (1950). Amer. F. Obstet. Gynec., 60, 1187.

Watson, H., Emslie-Smith, D., Herring, J., and Hill, I. G. W. (1960). Lancet, 2, 523.

\title{
Oil Mist Hazard and Piped Air Supplies
}

\author{
JOHN A. BUSHMAN,* L.M.S.S.A. ; PETER A. CLARK, $†$ M.B., M.C.PATH.
}

During recent years there has been a considerable increase in the use of piped air supplies in hospitals. In intensive therapy units this air may often be used to ventilate patients directly.

A system of this type was installed in the intensive therapy unit at Barnet General Hospital and has been in regular use from January 1965. The supply was provided by duplicate oil-lubricated Lacey-Hulbert compressors, each capable of delivering $5 \frac{1}{2} \mathrm{cu}$. ft. $(0.156 \mathrm{cu}$. m.) of air per minute at $100 \mathrm{lb} . /$ sq. in. (7 kg./sq. cm.). These compressors were installed in the cellar below the intensive therapy unit, together with a reservoir of $33 \mathrm{cu}$. ft. $(0.935 \mathrm{cu}$. m.) capacity. A Hymatic "rectifier" was installed to remove water. The compressed air was delivered by copper piping to five bedside outlets each equipped with B.O.C. flowmeters.

Some months later it was noticed that some of the flowmeter bobbins were inclined to stick. One of the flowmeters appeared to be slightly oily, and the possibility of oil mist contamination

\footnotetext{
* Anaesthetic Registrar, Barnet General Hospital, Barnet, Herts. Research Fellow, Department of Anaesthesia, University of Birmingham. t Consultant Pathologist, Barnet General Hospital, Barnet, Herts.
}

was considered. When the valve of this flowmeter was completely opened to a point far beyond its normal setting, a ripple of oil could be seen on the side of the meter tube (Fig. 1). This excessive air flow had presumably dislodged a quantity of oil trapped below the valve.

An investigation to find the extent of this oil contamination was started. In view of the extremely small quantities of oil mist likely to be present in the air, it was decided to use a fluorimetric technique for oil estimation (Parker and Barnes, 1960).

\section{Methods}

Oil mist was collected by passing a known volume of air through filter paper held in a special device consisting of two recessed flanges fitted with hose connexions between which pairs of filter paper discs were held by washers and a spacer. The filter papers used in this work were Whatman paper No. 41, which will cope with low-pressure flows of at least 10 litres per minute. Owing to the rather open nature of the paper, two discs were used in each flange. The papers were 